\title{
Scintigraphic Evaluation of Cold Thyroid Nodules
}

\author{
Hryoshimaru Oyamada and Toshio Tabei \\ Nuclear Medicine Section, Department of Diagnostic Radiology, \\ National Cancer Center Hospital, Tokyo 104
}

\begin{abstract}
Oxamada, H. and TABEI, T. Scintigraphic Evaluation of Cold Thyroid Nodules. Tohoku J. exp. Med., 1977, 123 (4), 315-321 — Scintigraphic patterns of cold thyroid nodules taken by the scintillation camera with radioactive iodine131 were reported. Previous reports published by others on this subject were based on the scintillation scanner which gave us less sharp resolution than the scin. tillation camera. Our data indicate that the defect pattern is largely dependent upon the existence of the capsule as well as the size of the nodule. In general, a benign nodule shows defect having a rather smooth margin with somewhat distended normal thyroid tissue, whereas malignant one, if it has no capsule, shows an irregular or straight margin. However, the defect pattern of malignant nodule covered with a capsule is similar to that of benign nodule. A defect of the entire unilateral lobe and a highly irregular-shaped defect spread over bilateral lobes are suggestive of malignancy. These findings seem to be generally similar to those reported by others. However, pull-up phenomenon of lower pole coexisting with the defect in the upper half is highly suggestive of malignancy, especially of papillary type. As long as defect (negative) pattern is investigated, the diagnosis of cold nodule inevitably meets certain limitations. To avoid this problem, the radiopharmaceutical which exclusively concentrates in malignant nodule should be searched. Then, the scintigraphic diagnosis of thyroid nodule will become more reliable. - cold thyroid nodule; radioiodine- ${ }^{131} \mathrm{I}$; scintigram
\end{abstract}

Most of the thyroid nodules are visualized as defects on the ordinary scintigrams with radioactive iodine or Technetium-99m pertechnetate. Some previous papers have shown defect patterns for differential diagnosis between benign and malignant nodules (Meadows 1961; Miller et al. 1965; Kinoshita 1967; Ishikawa and Yasukochi 1968). However, these reports were based on the data taken by the scintillation scanner which has been known to give us less sharp resolution in contrast to the scintillation camera with a pin hole collimator.

When scintigram is taken by the scanner, the image resolution is always affected by the collimator, scan speed, spacing of scan lines, uptake per cent of radionuclide by the thyroid gland, the energy of gamma ray, etc. This fact brings us some troubles when we try to apply the patterns classified by somebody to the scintigrams obtained by our scanner of different type. On the other hand, the scintillation camera with a pin hole collimator offers relatively steady scintigrams even though different models are used.

Received for publication, April 20, 1977.

This work was supported in part by the grant for Cancer Research from the Ministry of Health and Welfare, Japan. 
This is to report the result of our studies on the scintigraphic patterns of cold thyroid nodules taken by the scintillation camera with ${ }^{131} \mathrm{I}$ in connection with their gross pathological findings.

\section{Materials and Methods}

The patients studied in this series were selected from the records between 1971 and 1975 under the following criteria: 1) Histologically the nodules were verified as carcinoma, adenoma, cyst, or colloid nodule. 2) The nodules were palpable. 3) Cold or relative cold nodules were noted on the scintigram taken with ${ }^{131} \mathrm{I}$. 4) The scintillation camera with a pin hole collimator was used. 5) The uptake of ${ }^{131} \mathrm{I}$ by normal thyroid tissue was enough for image assessment. 6) If nodules were more than one, they were separated enough not to be interfered with the image of the adjacent nodule. 7) No resection had been performed in any part of the thyroid gland.

There were 29 males and 114 females who satisfied the above criteria. The age distribution ranged from 15 to 77 for male and from 22 to 83 for female. The average ages were 47.4 and 47.7 , respectively.

The scintillation camera used in this study was Nuclear Chicago Pho/Gamma III initially and Pho/Gamma HP later. Preset counts ranged between 10,000 and 30,000. The dose administered to patients ranged from 50 to $100 \mu \mathrm{Ci}$ and the scintigram was taken a day after oral administration. In all patients an idoine-free diet was requested for 10 to 14 days before the test.

\section{Results}

There were 98 benign and 67 malignant nodules. Among the benign nodules, the smallest one which was visualized on the scintigram was $0.5 \mathrm{~cm}$ in diameter in the upper third, whereas the largest nodule which was not visualized was $2.0 \mathrm{~cm}$ in the isthmic portion. As for the malignant nodules, the smallest one detected was $0.9 \mathrm{~cm}$ in the upper third, while the largest one missed on the scan was $1.8 \mathrm{~cm}$ in the middle third.

The defect pattern caused by either benign or malignant lesion is influenced by the size of the lesion, pathological feature of the border between the lesion and
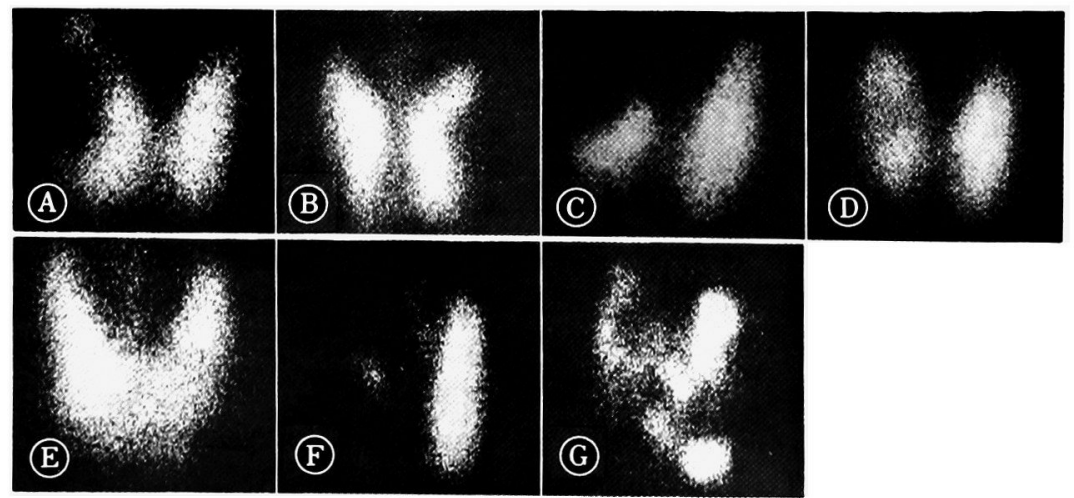

Fig. 1. Representative cases for each type (see the text).

Type A: colloid nodule; Type B: papillary carcinoma, capsule (+); Type C: papillary carcinoma, capsule (-); Type D: papillary carcinoma, capsule $(+)$; Type E: papillary carcinoma, capsule (-); Type F: papillary carcinoma, capsule (-); Type G: papillary carcinoma, capsule (-). 
normal thyroid tissue, and also by the radioiodine concentration ratio between the lesion and the surrounding normal tissue. The projection of the detector head also has some meanings for image visualization.

In this series, oblique projections, either right or left and/or both, were used in many cases to obtain the best image besides ordinary anterior projection. The defect patterns (Fig. 1) were classified as shown in Table 1 which indicates the correlation between the pathological nature of the nodules and the defect patterns on the scintigrams. Here, each type indicates the following criterion:

TABLE 1. Schematic drawings of each defect type and the number of nodules

\begin{tabular}{|c|c|c|c|c|c|}
\hline & \multirow{2}{*}{ Type } & \multicolumn{2}{|c|}{ Benign } & \multicolumn{2}{|c|}{ Malignant } \\
\hline & & Number & $\underset{(\max . / \min .)}{\operatorname{Size}}$ & Number & $\underset{(\max . / \mathrm{min})}{\mathrm{Size}}$ \\
\hline A & 2 & 61 & $\begin{array}{l}\mathrm{cm} \\
7.6 / 1.2\end{array}$ & 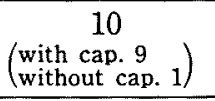 & $\begin{array}{l}c m \\
5.0 / 1.6\end{array}$ \\
\hline B & su & 15 & $6.0 / 1.0$ & $\begin{array}{c}7 \\
\left(\begin{array}{l}\text { with cap. } 2 \\
\text { without cap. 5) }\end{array}\right)\end{array}$ & $4.0 / 1.7$ \\
\hline $\mathrm{C}$ & $M$ & 1 & 3.0 & $\begin{array}{c}17 \\
\left(\begin{array}{l}\text { with cap. } 1 \\
\text { without cap. 16 }\end{array}\right)\end{array}$ & $3.8 / 1.3$ \\
\hline $\mathrm{D}$ & & 3 & $2.5 / 0.7$ & 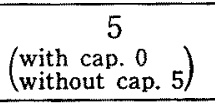 & $2.2 / 1.3$ \\
\hline $\mathrm{E}$ & & 11 & $2.0 / 0.5$ & $\begin{array}{c}8 \\
\text { (with cap. 1 } \\
\text { without cap. 7) }\end{array}$ & $4.0 / 0.8$ \\
\hline $\mathrm{F}$ & & 1 & & $\left(\begin{array}{c}12 \\
\text { with cap. } 1 \\
\text { without cap. } 9 \\
\text { no surger y } 2\end{array}\right)$ & \\
\hline G & & 0 & & $\frac{1}{\text { (witout cap. 1) }}$ & \\
\hline & Total & & 92 & 6 & \\
\hline
\end{tabular}

cap. indicates the capsule.

Type A: Cold or relative cold area with a smooth margin. The surrounding normal thyroid tissue shows some distension or protrusion.

Type B: Cold or relative cold area with a smooth margin but without distension or protrusion of the surrounding thyroid tissue.

Type C: Defect with a straight or irregular margin.

Type D: A belt-like transverse defect in the area close to the upper lobe.

Type E: Simple low uptake pattern with or without protrusion. Its margin is rather irregular.

Type F: Total defect of unilateral lobe or nearly total defect with a distorted distribution pattern in one lobe.

Type G: Highly irregular-shaped defect spread over bilateral lobes, showing rather patchy pattern. 
The number of nodules visualized on the scan was 92 for benign and 60 for malignant groups. 61 out of 92 benign nodules were classified as Type A (66\%), and the numbers of nodules in the remaining types were 15,1,3,11, 1 and zero in order. On the other hand, the number of malignant nodules classified as Type A amounted to only $10(17 \%)$, and the remaining types included the following numbers: 7, 17, 5, 8, 12 and 1 in order. Types $\mathrm{C}$ and $\mathrm{F}$ were most frequently found in malignant group and the ratios were $28 \%$ and $20 \%$, respectively, but only $2 \%$ as a total for both types in the benign group. From these facts, it can be said that nearly half of the malignant nodules possibly show either Type $\mathrm{C}$ or $\mathrm{F}$. However, the defect pattern seems to be largely dependent upon the existence of the capsule.

In the column of malignant nodules, the number for each type was further divided into two groups: with or without capsules. 9 out of 10 malignant nodules in Type A had capsules. On the other hand, 16 out of 17 malignant nodules of Type $\mathrm{C}$ and 9 out of 10 malignant nodules of Type $\mathrm{F}$ had no capsule.

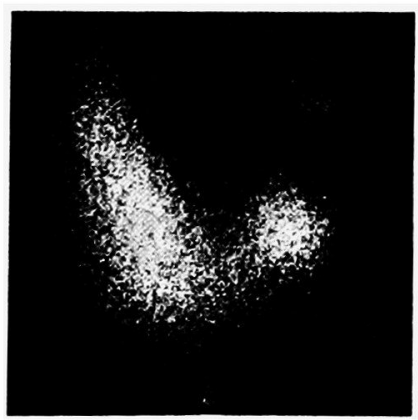

Fig. 2. A case showing "pull-up" phenomenon. Papillary carcinoma.

TABLE 2. Correlation between pull-up phenomenon and the pathological findings (see the text)

Malignant nodules

\begin{tabular}{|c|c|c|c|c|c|c|c|}
\hline & \multicolumn{3}{|c|}{ Pull-up (+) } & \multicolumn{3}{|c|}{ Pull-up (-) } & \multirow{2}{*}{ Total } \\
\hline & With cap. & Without cap. & Total & With cap. & Without cap. & Total & \\
\hline $\begin{array}{c}\text { Number of } \\
\text { nodules }\end{array}$ & 0 & $\begin{array}{cc}8 \\
\text { papillary } 8 \\
\text { follicular } 0\end{array}$ & 8 & $\begin{array}{cc}5 \\
\text { papillary } 3 \\
\text { follicular } 2\end{array}$ & $\begin{array}{c}3 \\
\text { papillary } 3 \\
\text { follicular } 0\end{array}$ & 8 & 16 \\
\hline
\end{tabular}

Benign nodules

\begin{tabular}{cccccc}
\hline & \multicolumn{5}{c}{ Pull-up (+) } \\
\cline { 2 - 5 } & Pseudocyst & $\begin{array}{c}\text { Degenerated } \\
\text { follicular adenoma }\end{array}$ & Total & Pull-up (-) & Total \\
\hline $\begin{array}{r}\text { Number of } \\
\text { nodules }\end{array}$ & 1 & 1 & 2 & 9 & 11 \\
\hline
\end{tabular}


Defect or decreased uptake pattern with a smooth margin but without distension of normal tissue (Type B) was noted in $16 \%$ of benign nodules and in $12 \%$ of malignant ones. Five out of 7 malignant nodules of this type had no capsule.

Cases having a malignant nodule of less than $3.5 \mathrm{~cm}$ in diameter in the upper half of one lobe were summarized in Table 2 in regard to pull-up phenomenon of its lower pole. This phenomenon (Fig. 2) was noticed by us some years ago. Of 16 malignant nodules, 8 showed pull-up phenomenon and other 8 did not. All in the former group had no capsule and were papillary type histologically. Five in the latter group had a capsule and the remaining 3 did not. There were 11 benign nodules, only 2 of which showed pull-up phenomenon. One was a degenerated follicular adenoma which measured $2.5 \mathrm{~cm}$ in diameter and considered to have had a tendency of shrinking. Another one was a pseudocyst which measured $0.7 \mathrm{~cm}$ in diameter and could well be in the course of shrinkage.

\section{Comment}

Although there are some nodules which show concentration of radioactive iodine (i.e., functioning adenoma), most of the thyroid nodules which we encounter are shown clinically as a defect or a low uptake area on the thyroid images. Since thyroid scanning started with radioactive idoine-131, there have been some comments concerning differential diagnosis between benign and malignant nodules from the basis of their defect patterns (Meadows 1961; Miller et al. 1965; Kinoshita 1967; Ishikawa and Yasukochi 1968). However, the defect pattern is influenced by many factors and we feel, in many occasions, it is difficult to differentiate various conditions on the basis of defect pattern only. This has been already pointed out by other workers (Attie 1960; Shimaoka and Sokal 1964). But, it is generally accepted that benign nodules show a rather smooth defect margin whereas malignant ones show an irregular defect pattern or a clear-cut straight margin. Entire defect of unilateral lobe is also said to be suspicious of thyroid cancer. We feel that these comments are generally true. But the fact that thyroid cancer can be encapsulated brings us always some confusions on the scintigraphic images. This is apparent from our results.

In this study, we summarized the defect patterns of thyroid nodules on the scintigrams taken with ${ }^{131} \mathrm{I}$ in relation to their pathological appearances. The malignant nodule, if it has no capsule, often shows a straight margin or distorted defect pattern (Types $\mathrm{C}$ and F). On the other hand, simply decreased concentration with an indistinct margin (Type E) is equally noted in both benign and malignant nodules when they are not so large. If a benign nodule is large enough, the margin of the defect frequently shows a smooth and concave pattern with somewhat distended normal tissue. The cancers of encapsulated type also show the similar pattern.

Kinoshita (1967) and Ishikawa and Yasukochi (1968) reported the defect patterns caused by various disorders. Although they did not comment anything about the capsule and their reports were based on the scintigram taken by the 
scintillation scanner, the patterns analyzed by them seem to be generally similar to our results.

In our series, the isthmic portion is the area where the scintigram sometimes fails to show defect. This is mostly due to low concentration of radioiodine in this area. In the middle and lower thirds, relatively large nodules occasionally failed to be visualzied in comparison with the upper third. These differences are partly due to the thickness of normal thyroid tissue surrounding the nodules. However, there are various nodules which differ in their functional status; so-called hyperfunctional, functional, hypofunctional, and nonfunctional. These conditions largely affect the image of the nodule. A normally functioning nodule can never be visualized as a defect. On the other hand, if a non-functioning nodule is covered with normal thyroid tissue with a certain thickness, such a nodule will be shown as either normally functioning or hypofunctioning nodule.

In our series, autoradiography was not performed and we are concerned only about gross marginal status of the nodule on the specimen. Some workers (Meadows 1961; Shimaoka and Sokal 1964) reported the results of thyroid scanning in terms of functional status of each nodule. It is generally accepted that the hyperfunctioning nodule can rarely be cancer. Except such a hyperfunctioning nodule, the nodules of other types cannot be judged about their functional status on the scintigram image alone because of unknown amount of normally functioning tissue close to the nodule. In general, the radiopharmaceuticals which are picked up by normally functioning tissue and visualize the diseased area as a defect has always certain limitations in detecting the lesions. In this regard, pull-up phenomenon is worthy of attention though there exists some physiological asymmetry (Ishikawa and Yasukochi 1968). From our results, it can be said that when the defect in the upper half arza of one lobe coexists with the lower pole which is pulled up significantly, such a defect is highly suspicious of carcinoma, especially of papillary type.

Instead of negative visualization of thyroid nodules, if positive visualization of thyroid cancer comes real, scintigraphic diagnosis will certainly advance. For this purpose, ${ }^{131} \mathrm{Cs}$ had been used for some time (Uchiyama 1969). But, because of its inconsistent results it is not in use anymore. Gallium-67 citrate has been used occasionally for imaging thyroid malignancies and it has been noted that some anaplastic cell carcinoma and reticulum cell sarcoma can be shown as a hot spot. However, more frequently occurring papillary and follicular carcinomas have failed to concentrate this radiopharmaceutical (Higashi and Nakayama 1972; Kaplan et al. 1974; Heidendal et al. 1975; Oyamada 1975). Mori et al. (1974) reported a fairly good result with ${ }^{99 \mathrm{~m} T c-l a b e l e d ~ b l e o m y c i n ~ f o r ~ t h e ~ d i a g n o s i s ~ o f ~}$ thyroid cancer. But there are no such reports published by others. This may be due to technical difficulty of its preparation.

Recently, Thallium-201 has called our attentions for positive visualization of thyroid cancer. It is now under extensive studies and we need more experiences before we come to conclusion. 
At present, ${ }^{131} \mathrm{I}$ is gradually being switched to ${ }^{123} \mathrm{I}$. However, ${ }^{123} \mathrm{I}$ also shows the diseased area in the thyroid gland as a defect generally. Our study reported here will present some clues for the scintigraphic study of thyroid nodules.

\section{References}

1) Attie, J.N. (1960) The use of radioactive iodine in the evaluation of thyroid nodules. Surgery, 47, 611-614.

2) Heidendal, G.A.K., Roos, P., Thijs, L.G. \& Wiener, J.D. (1975) Evaluation of cold areas on the thyroid scan with ${ }^{87} \mathrm{Ga}$-citrate. $J$. nucl. Med., 16, 793-794.

3) Higashi, T. \& Nakayama, Y. (1972) Clinical evalultion of ${ }^{87}$ Ga-citrate scanning. $J$. nucl. Med., 13, 196-201.

4) Ishikawa, D. \& Yasukochi, H. (1968) Readings on thyroidscintigrams. Nipp. Acta radiol., 28, 1039-1059.

5) Kaplan, W.D., Holman, B.L., Selenkow, H.A., Davis, M.A., Holmes, R.A., Isitman, A.T. \& Chandler, H.L. (1974) ${ }^{87} \mathrm{Ga}$-citrate and the nonfunctioning thyroid nodule. J. nucl. Med., 15, 424-427.

6) Kinoshita, F. (1967) Clinical Nuclear Medicine. edited by H. Kakehi, H. Irie \& H. Hiramatsu, Asakura Shoten, Tokyo. (Japanese)

7) Meadows, P.M. (1961) Scintillation scanning in the management of the clinically single thyroid nodules. J. Amer. med. Ass., 177, 229-234.

8) Miller, J.M., Hamburger, J.I. \& Mellinger, R.C. (1965) The thyroid scintigram. II. The cold nodule. Radiology, 85, 702-710.

9) Mori, T., Odori, T., Sakamoto, T., Hamamoto, K., Onoyama, Y. \& Torizuka, K. (1974) Clinical results of ${ }^{8 \theta m}$ Te labelled bleomycin scintigraphy in various malignant and benign diseases: Comparison with ${ }^{67} \mathrm{Ga}$-scintigraphy. Jap. J. clin. Oncol., 4, 133-144.

10) Oyamada, H. (1975) Atlas of Head and Neck Tumors. edited by K. Nakahara \& C. Taketa, Nakayama Shoten, Tokyo. (Japanese)

11) Shimaoka, K. \& Sokal, J.E., (1964) Differentiation of benign and malignant thyroid nodules by scintiscan. Arch. intern. Med., 114, 36-39.

12) Uchiyama, G. (1969) Thyroid gland-Differential diagnosis of thyroid tumor with radioactive Cesium. Jap. J. Cancer Clin., 15, 252-253. (Japanese) 